OPEN ACCESS

Edited by:

Ralf Georg Dietzgen,

The University of Queensland,

Australia

Reviewed by:

Steve Wylie,

Murdoch University, Australia

S. V. Ramesh,

Indian Council of Agricultural

Research (ICAR), India

*Correspondence:

Junmin Li

zilijunmin@126.com

Jianping Chen

jpchen2001@126.com

tThese authors have contributed

equally to this work.

Specialty section:

This article was submitted to

Virology,

a section of the journal

Frontiers in Microbiology

Received: 01 June 2017 Accepted: 05 September 2017 Published: 20 September 2017

Citation:

Li L, Andika IB, Xu Y, Zhang Y, Xin X Hu L, Sun Z, Hong G, Chen $Y$, Yan F, Yang J, Li J and Chen J (2017) Differential Characteristics

of Viral siRNAs between Leaves and Roots of Wheat Plants Naturally Infected with Wheat Yellow Mosaic

Virus, a Soil-Borne Virus.

Front. Microbiol. 8:1802.

doi: 10.3389/fmicb.2017.01802

\section{Differential Characteristics of Viral siRNAs between Leaves and Roots of Wheat Plants Naturally Infected with Wheat Yellow Mosaic Virus, a Soil-Borne Virus}

\author{
Linying Li1,2,3t, Ida Bagus Andika ${ }^{4+}$, Yu Xu ${ }^{2,3}$, Yan Zhang ${ }^{2,3}$, Xiangqi Xin ${ }^{5}$, Lifeng $\mathrm{Hu}^{2,3}$, \\ Zongtao Sun 2,3, Gaojie Hong',3, Yang Chen ${ }^{2,3}$, Fei Yan ${ }^{2,3}$, Jian Yang ${ }^{2,3}$, Junmin Li ${ }^{1,2,3 *}$ and \\ Jianping Chen ${ }^{1,2,3 *}$
}

${ }^{1}$ College of Plant Protection, Nanjing Agricultural University, Nanjing, China, ${ }^{2}$ The State Key Laboratory Breeding Base for Sustainable Control of Pest and Disease, Zhejiang Academy of Agricultural Sciences, Hangzhou, China, ${ }^{3}$ Key Laboratory of Biotechnology in Plant Protection of Ministry of Agriculture of China and Zhejiang Province, Institute of Virology and

Biotechnology, Zhejiang Academy of Agricultural Sciences, Hangzhou, China, ${ }^{4}$ Group of Plant-Microbe Interactions, Institute of Plant Science and Resources, Okayama University, Kurashiki, Japan, ${ }^{5}$ Institute of Plant Protection, Shandong Academy of Agricultural Sciences, Jinan, China

RNA silencing is an important innate antiviral defense in plants. Soil-borne plant viruses naturally infect roots via soil-inhabiting vectors, but it is unclear how antiviral RNA silencing responds to virus infection in this particular tissue. In this study, viral small interfering RNA (siRNA) profiles from leaves and roots of wheat plants naturally infected with a soil-borne virus, wheat yellow mosaic virus (WYMV, genus Bymovirus), were analyzed by deep sequencing. WYMV siRNAs were much more abundant in roots than leaves, which was positively correlated with the accumulation of viral RNA. WYMV siRNAs in leaves and roots were predominantly 21- and 22-nt long and equally derived from the positive- and negative-strands of the viral genome. WYMV siRNAs from leaves and roots differed in distribution pattern along the viral genome. Interestingly, compared to siRNAs from leaves (and most other reports), those from roots obviously had a lower A $\cup$ bias at the $5^{\prime}$-terminal nucleotide. Moreover, the expression of Dicer-like genes upon WYMV infection were differently regulated between leaves and roots. Our data suggest that RNA silencing in roots may operate differently than in leaves against soil-borne virus invasion.

Keywords: soil-borne plant viruses, wheat yellow mosaic virus, viral small interfering RNA, antiviral RNA silencing, deep sequencing

\section{INTRODUCTION}

Virus infection in plants is usually associated with the accumulation of virus-derived small interfering RNAs (vsiRNAs) that play essential roles in antiviral RNA silencing defense by degrading viral RNA in a sequence-specific manner (Llave, 2010; Zhang et al., 2015; Li M.L. et al., 2016). In the antiviral RNA silencing pathway, viral-derived double-stranded RNA (dsRNA) is processed by a ribonuclease III-like protein called Dicer or Dicer-like (DCL), to produce 21- to 24-nucleotide (nt) siRNAs. These are then incorporated into RNA-induced silencing complexes (RISCs) containing Argonaute (AGO) to mediate sequence-specific viral RNA degradation (Aliyari and Ding, 2009; Bologna and Voinnet, 2014). High-throughput sequencing and comprehensive 
analysis of vsiRNAs in infected plant samples have expanded our knowledge of the biogenesis of vsiRNAs and their participation in the regulation of host gene expression and virus-host interactions as well as in shaping the evolution of viruses (Llave, 2010; Zhu and Guo, 2012; Kutnjak et al., 2015; Hadidi et al., 2016). In particular, recent comparative studies of siRNAs of the same virus in different host plants (genotypes), or siRNAs of different viruses (strains) in the same host plant, have provided deeper insights into the link between viral pathogenicity and vsiRNA profiles (Naveed et al., 2014; Margaria et al., 2015, 2016; Ogwok et al., 2016). Other reports also suggest that the biogenesis of vsiRNAs of plant viruses differs in their plant hosts from that in their insect vectors, for example, with tomato spotted wilt virus (genus Tospovirus) in the host Arachis hypogaea and the vector Frankliniella fusca (Fletcher et al., 2016), and with rice stripe virus (genus Tenuivirus) in the hosts Oryza sativa or Nicotiana benthamiana and the vector Laodelphax striatellus (Xu et al., 2012). Nevertheless, most studies of vsiRNA profiles in plants have used infected leaf tissue, and there is little evidence from other tissues. In our recent study of cucumber green mottle mosaic virus (genus Tobamovirus) siRNAs from leaves and fruits, vsiRNAs in leaves were predominantly derived from the viral positive-strand RNA, whereas those in fruits were derived equally from both strands, suggesting that the biogenesis of vsiRNAs might differ in the different tissues (Li J. et al., 2016).

Most plant viruses are transmitted to leaves by arthropod vectors, but some soil-inhabiting organisms, such as plasmodiophorids and nematodes can transmit viruses to plant roots (Hull, 2013). Thus, successful multiplication in plant roots is important for the life cycle of soil-borne viruses. There are few studies of vsiRNA profiles in root tissues and none that have analyzed vsiRNAs in roots from the viruses that infect the plants through soil-inhabiting vectors (Andika et al., 2016). Given the large physiological differences between the underground root and the aerial parts of plants, it is possible that antiviral defense might work differently in plant roots than in leaves and shoots. Since DCL proteins are the primary key enzymes in the RNA silencing pathway, investigation of vsiRNA profiles in roots may provide new insights into the antiviral RNA silencing mechanism against soil-borne virus invasion.

Wheat yellow mosaic virus (WYMV, genus Bymovirus and family Potyviridae) is an economically important pathogen of winter wheat (Triticum aestivum), causing serious yield losses in Japan and China (Namba et al., 1998; Han et al., 2000). WYMV is transmitted by Polymyxa graminis, an obligate soilinhabiting fungus-like protist (Kanyuka et al., 2003). Like other viruses in the genus Bymovirus, the WYMV genome consists of two positive single-stranded RNAs (RNA1 and RNA2). RNA1 encodes a large polyprotein that is proteolytically processed into eight proteins; P3, 7k, cylindrical inclusion protein (CI), 14k, genome-linked viral protein ( $\mathrm{VPg}$ ), nuclear inclusion protein a-proteinase (NIa-Pro), nuclear inclusion protein $\mathrm{b}(\mathrm{Nib})$, and coat protein $(\mathrm{CP})$. RNA2 encodes a polyprotein processed into a $28-\mathrm{kDa}$ protein (P1) and a 73-kDa protein (P2) (Namba et al., 1998; Adams et al., 2005). P2 is unique to bymoviruses; it is essential for the transmission vectored by $P$. graminis and plays a role in the formation of membranous compartments associated with genome replication of WYMV (Dessens and Meyer, 1996; Adams et al., 2001; Sun et al., 2014). In the monopartite viruses within the family Potyviridae, the helper component protease (HC-Pro), the P1 protein, or P1N-PISPO function as RNA silencing suppressors, but the silencing suppressor of bymoviruses has not been identified (Valli et al., 2006, 2017; Tatineni et al., 2012; Mingot et al., 2016; Untiveros et al., 2016). The $\mathrm{N}$-terminal region of $\mathrm{P} 1$ of bymoviruses including WYMV, barley yellow mosaic virus (Kashiwazaki et al., 1991) and barley mild mosaic virus (Kashiwazaki, 1996) show significant amino acid homologies with the active domains of the HC-Pro of monopartite potyviruses such as potato virus Y, plum pox virus, tobacco etch virus and tobacco vein mottling virus (Namba et al., 1998). Nonetheless, the roles of P1 in the multiplication and life cycle of bymoviruses need further investigation.

In the present study, the profiles of WYMV vsiRNA derived from leaves and roots of infected wheat plants were comprehensively characterized by deep sequencing. In addition, the expressions of DCL and AGO gene transcripts in WYMVinfected leaves and roots were analyzed by quantitative PCR.

\section{MATERIALS AND METHODS}

\section{Sample Collection and Total RNA Extraction}

WYMV-infected plant samples were obtained from a wheat nursery in Linyi, Shandong Province of China, where it was continually used to screen WYMV resistance wheat cultivars during 2012-2016. Wheat plants (cultivar Linmai4) with fully developed stem and jointing as well as having typical yellow mosaic symptoms were collected from the diseased nursery in March, 2016. In parallel, virus-free plants of the same cultivar were obtained from an adjacent field (less than $10 \mathrm{~m}$ distance) as a control. Three independent replicates of virus-free and WYMV-infected root and leaves samples were used for the experiment. Roots of each wheat plant $(50 \mathrm{mg})$ were cut into small pieces and ground to a fine powder under liquid nitrogen. Total RNA was extracted using Trizol reagent (Invitrogen, CA, United States) according to the manufacturer's instructions. The integrity and quality of RNA samples were evaluated by denaturing agarose gel electrophoresis and 2100 Bioanalyzer (Agilent, United States). The presence of WYMV in the roots was confirmed for all samples with a One Step RT-PCR Kit (TOYOBO, Japan) using WYMV-specific primers (W-F, 5'-CAAGGTTGAGGCAGATCGTG-3'; W-R: 5'-C AGATGCGCCGTGTTTCATA-3').

\section{Small RNA Sequencing and Bioinformatics Analysis}

About $5 \mu \mathrm{g}$ of total RNA was extracted from each of the leaves and roots of virus-free and WYMV-infected plants for the preparation of small RNA (sRNA) libraries using the Illumina TruSeq Small RNA Sample Preparation Kit (Illumina, United States), while the remaining RNA was used for reverse 
TABLE 1 | The read number of small RNAs (sRNAs) and WYMV-derived small interfering RNAs (vsiRNAs) from virus-infected wheat plants.

\begin{tabular}{|c|c|c|c|c|c|c|}
\hline & \multicolumn{3}{|c|}{ Leaves } & \multicolumn{3}{|c|}{ Roots } \\
\hline & $\begin{array}{c}\text { Replicate } 1 \\
\text { L1 }\end{array}$ & $\begin{array}{c}\text { Replicate } 2 \\
\text { L2 }\end{array}$ & $\begin{array}{c}\text { Replicate } 3 \\
\text { L3 }\end{array}$ & $\begin{array}{c}\text { Replicate } 1 \\
\text { R1 }\end{array}$ & $\begin{array}{c}\text { Replicate } 2 \\
\text { R2 }\end{array}$ & $\begin{array}{c}\text { Replicate } 3 \\
\text { R3 }\end{array}$ \\
\hline sRNAs (total) & $5,214,377$ & $5,035,946$ & $4,659,474$ & $9,507,299$ & $10,021,025$ & $11,227,881$ \\
\hline vsiRNAs (total)* & 103,581 & 143,327 & 22,997 & 778,744 & 702,980 & 791,399 \\
\hline vsiRNA/sRNAs (total) & $1.99 \%$ & $2.85 \%$ & $0.49 \%$ & $8.19 \%$ & $7.02 \%$ & $7.05 \%$ \\
\hline sRNAs (unique) & 838,479 & $1,388,780$ & $1,071,118$ & $1,714,971$ & $2,188,254$ & $2,245,279$ \\
\hline vsiRNAs (unique) & 35,336 & 36,838 & 12,206 & 88,686 & 91,937 & 97,287 \\
\hline vsiRNAs/sRNAs (unique) & $4.21 \%$ & $2.65 \%$ & $1.14 \%$ & $5.17 \%$ & $4.20 \%$ & $4.33 \%$ \\
\hline
\end{tabular}

* Raw reads which were mapped to the WYMV genome allowing for one mismatch.

transcription-quantitative PCR (RT-qPCR) analysis. sRNA highthroughput sequencing was carried out on an Illumina HiSeq 2500 at LC-BIO (Hangzhou, China). Preliminary treatment of raw data was performed as described previously (Li et al., 2013). Briefly, after removal of the $3^{\prime}$ adaptor, low quality and junk sequences using the FASTX-Toolkit ${ }^{1}$, sRNAs with length of 18 - to 30-nt were extracted and collapsed for further bioinformatics analysis. To identify WYMV-derived siRNAs, processed reads derived from both leaves and roots of infected and virus-free wheat libraries were mapped to the WYMV genome (NCBI accession No.: PRJNA15358) using Bowtie software ${ }^{2}$ allowing for one mismatch. To facilitate the comparisons between different sized libraries, identified vsiRNA raw reads counts were scaled to "Reads Per Million" (RPM) based on the total sRNA read numbers of the corresponding library. Downstream analyses for the vsiRNAs were carried out using custom perl scripts and Linux bash scripts.

\section{Reverse Transcription-Quantitative PCR}

Equal quantities of total RNA (100 ng) from leaves and roots of virus-free and WYMV-infected plants were used for cDNA synthesis. The first-strand cDNAs were generated from the extracted total RNAs using the Fast Quant RT Kit (Tiangen, Beijing, China) and RT-qPCR was performed on the ABI 7900HT (Applied Biosystems). Primer sets specific for WYMV (WYMV-CP), wheat AGO1 (TaAGO1), AGO2 (TaAGO2), AGO4 (TaAGO4), DCL2 (TaDCL2), and DCL4 (TaDCL4) were used for RT-qPCR and ubiquitin (TaU) was used as a reference gene. All the primers used for RT-qPCR were listed in Supplementary Table S1. The RT-qPCR reaction was run in a final volume of $20 \mu \mathrm{l}$ containing $10 \mu \mathrm{l}$ of PCR buffer, $0.6 \mu \mathrm{l}$ of each primer $(10 \mu \mathrm{M} / \mathrm{l}), 1 \mu \mathrm{l}$ of template cDNA, and $7.8 \mu \mathrm{l}$ of DEPC $\mathrm{H}_{2} \mathrm{O}$. The reaction conditions were: $94^{\circ} \mathrm{C}$ for $3 \mathrm{~min}$, followed by 40 cycles of $94^{\circ} \mathrm{C}$ for $20 \mathrm{~s}, 58^{\circ} \mathrm{C}$ for $20 \mathrm{~s}$, and $72^{\circ} \mathrm{C}$ for $20 \mathrm{~s}$.

\section{Statistical Analysis}

One-way ANOVA was performed in this study using Originpro 8.5 and values of $P<0.01$ were considered significantly different between the samples.

${ }^{1}$ http://hannonlab.cshl.edu/fastx_toolkit/

${ }^{2}$ http://bowtie-bio.sourceforge.net

\section{RESULTS AND DISCUSSION}

\section{Overview of WYMV-Derived siRNAs}

Deep sequencing yielded 5,214,377 (838,479 unique), 5,035,946 (1,388,780 unique), and 4,659,474 (1,071,118 unique) total small reads (18-30 nt) from the three leaf libraries, and 9,507,299 (1,714,971 unique), 10,021,025 (2,188,254 unique), and $11,227,881(2,245,279$ unique) total small reads (18-30 nt) from the three root libraries. Large numbers of sRNA reads from both leaf and root libraries were mapped to the WYMV genome (Table 1 and Supplementary File S1), whereas only a very small number $(<100$ reads) were obtained from the virus-free samples (data not shown). The total and unique vsiRNAs respectively accounted for $0.49-2.85$ and $1.14-4.21 \%$ of the total sRNAs in leaves, while the corresponding values for root samples were $7.02-8.19$ and $4.20-5.17 \%$ (Table 1). Sequencing results indicated that vsiRNAs were much more abundant in roots than in leaves (Table 1 and Figure 1B). Our RT-qPCR showed that accumulation of WYMV was about 30fold higher in roots than in leaves (Figure 1A), which was positively correlated with the accumulation of vsiRNAs. This result suggests that the high levels of viral replication might provide more dsRNA substrates for the generation of vsiRNAs in roots by the host RNA silencing machinery. Previous studies have also shown that some soil-borne viruses accumulate to a higher level in roots than leaves (Andika et al., 2005, 2013; Gosalvez-Bernal et al., 2008). In contrast to our results with WYMV, two other soil-borne viruses, beet necrotic yellow vein virus (BNYVV, genus Benyvirus) and Chinese wheat mosaic virus (genus Furovirus) accumulate to higher levels in roots than leaves of $N$. benthamiana plants, but these higher accumulations are not associated with more abundant vsiRNAs in roots (Andika et al., 2005, 2013). Nevertheless, in those studies the viruses were inoculated into the plants by mechanical rub-inoculation of the leaves. Thus, antiviral RNA silencing may respond differently depending on the route of entry of virus into the plant or the viral transmission method. The positive correlation between virus accumulation levels and the abundance of WYMV siRNAs in roots may suggest that initially plant antiviral silencing strongly responds to WYMV multiplication in roots by actively processing viral RNAs into siRNAs, but this antiviral response seems to be ineffective in limiting viral accumulation in roots. As suggested 

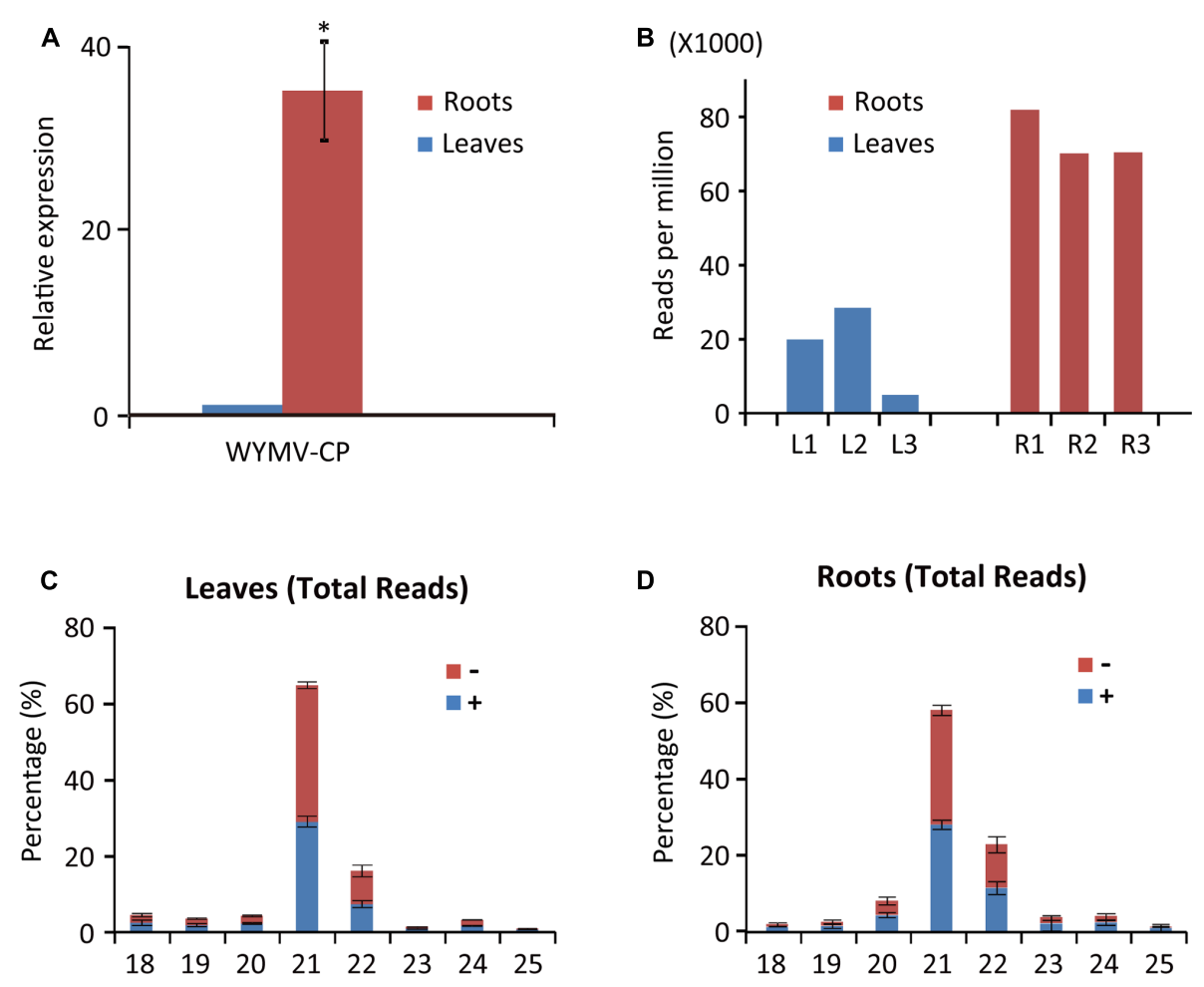

FIGURE 1 | Abundance of WYMV RNA and siRNAs in leaves and roots of wheat plants. (A) RT-qPCR analysis of WYMV RNA accumulation. (B) Abundance of WYMV siRNAs. (C,D) Size distribution of WYMV siRNAs. "-" and "+" indicate siRNAs derived respectively from the complementary (negative) or positive viral genomic strands. Asterisk indicates significant difference at $P<0.01$ (one-way ANOVA).

previously (Andika et al., 2016), some soil-borne viruses may be more adapted to roots than aerial tissue for their efficient transmission and multiplication. The suppression activities of RNA silencing suppressors encoded by BNYVV and tobacco rattle virus (genus Tobravirus) are more effective in roots than leaves (Andika et al., 2012). It is possible that like other soilborne viruses, WYMV suppresses antiviral RNA silencing more effectively in roots than in the aerial parts of the plant.

WYMV siRNA populations derived from leaves and roots were predominantly 21- and 22-nt long (Figures 1C,D), suggesting they were the products of DCL4 and DCL2 (Deleris et al., 2006; Diaz-Pendon et al., 2007). WYMV siRNAs from both leaves and roots had approximately equal proportions of sense and antisense sequences (Figures 1C,D), consistent with the view that viral dsRNA replication intermediates are the main substrates for vsiRNA production (Ahlquist, 2002; Ding, 2010).

\section{Differential vsiRNA Distribution Patterns between Leaves and Roots along the Viral Genome}

To examine the vsiRNA distribution pattern, 21- and 22-nt vsiRNAs were aligned to the WYMV genome. Although total vsiRNA numbers differed between the three biological replicates, the vsiRNA distribution patterns were similar within each leaf and root samples, confirming the reliability of the data (Figure 2). The 21- and 22-nt siRNAs were distributed along the entire RNA1 and RNA2 sequences including the untranslated regions (UTRs) (Figure 2). It was particularly noticeable in RNA2 segment of root samples, vsiRNAs were more densely mapped to $3^{\prime}$-UTR, suggesting that this region is preferentially targeted by DCL for vsiRNA biogenesis (Figure 2C). Multiple vsiRNA hotspots were identified in both RNA segments, but the position of those hotpots differed between leaf and root samples. Interestingly, in leaf (but not in root) samples, a very prominent hotspot for a single sense strand 21-nt vsiRNA occurred in the $3^{\prime}$-UTR region of RNA2 (nt position 3379-3399), while in root samples, hotspots composed of several negative strand vsiRNAs were observed in the similar region of $3^{\prime}$-UTR region of RNA2 (Figures 2B,C). Highly structured singlestranded viral RNA potentially responsible for vsiRNA hotspots generation as demonstrated previously (Molnar et al., 2005). However, examination of this region using RNAfold ${ }^{3}$ showed no clear relationship between the hotspot and predicted secondary structure (data not shown). Furthermore, three vsiRNA libraries (replicates) were mixed, and unique 21- and 22-nt vsiRNAs were extracted and analyzed. Leaf and root libraries shared substantial numbers of common vsiRNAs, but root libraries had many more tissue-specific vsiRNAs than leaf libraries (Supplementary Figure S1), indicating that the higher abundance of vsiRNAs in roots reflects more diverse Dicer cleavage sites.

\footnotetext{
${ }^{3}$ http://rna.tbi.univie.ac.at/cgi-bin/RNAWebSuite/RNAfold.cgi
} 


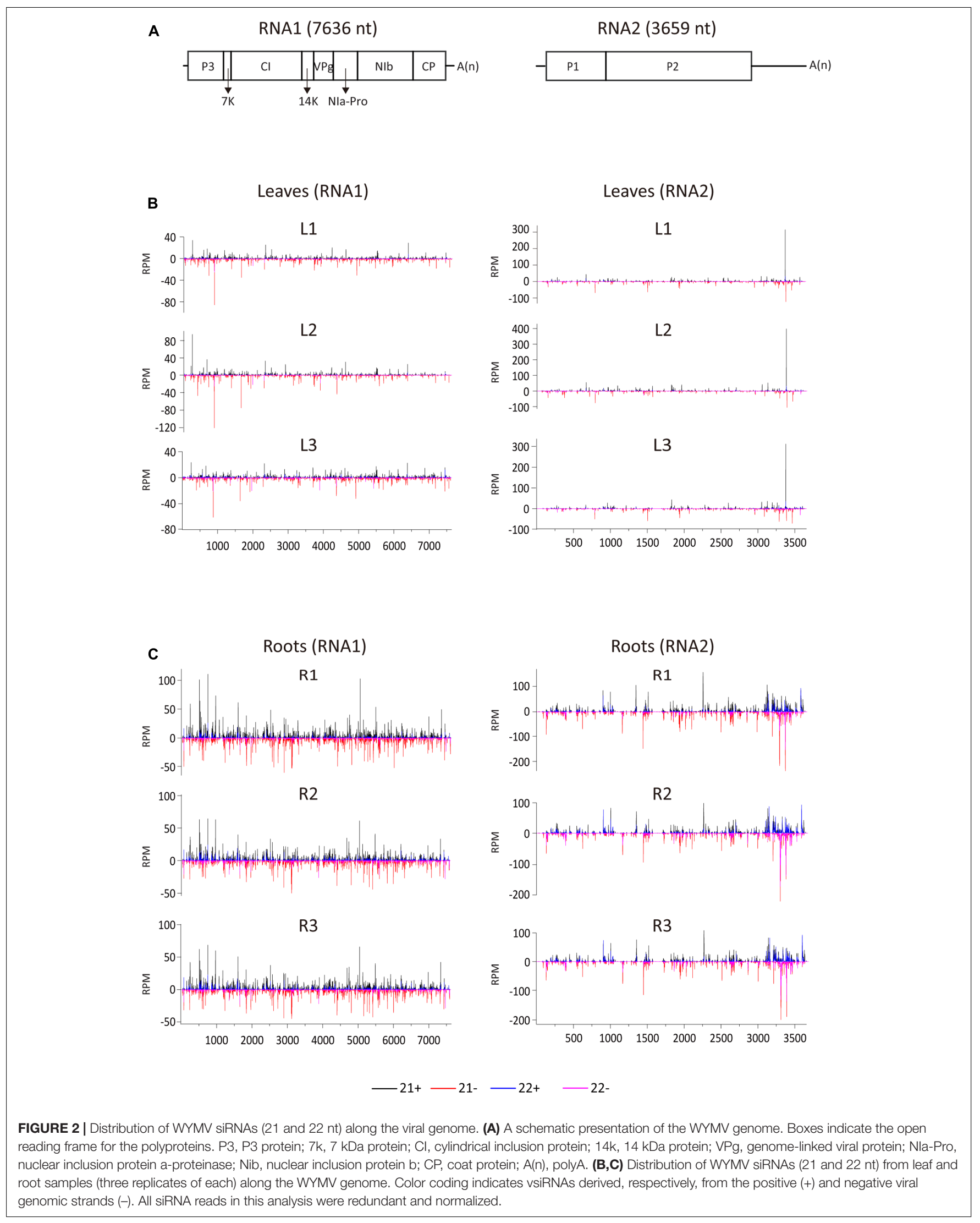


A

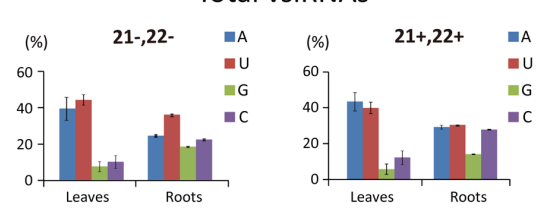

\section{B}

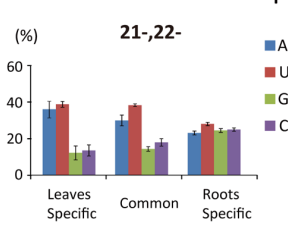

\section{Unique vsiRNAs}



C

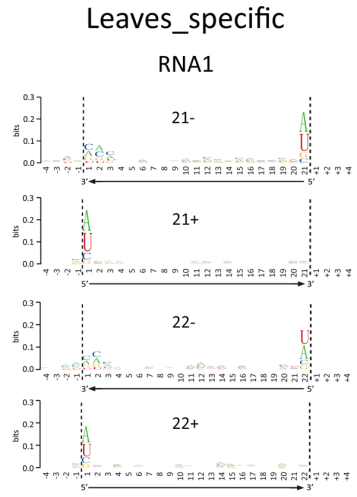

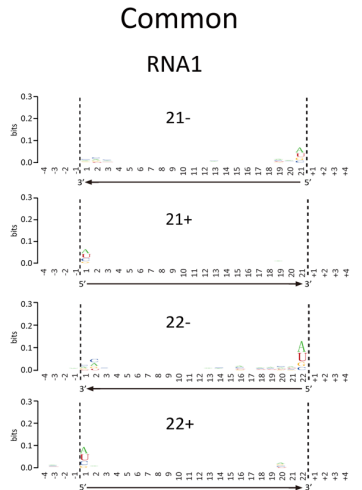

FIGURE $3 \mid 5^{\prime}$-Terminal nucleotide profile of WYMV siRNAs. (A,B) Distribution patterns of the $5^{\prime}$-terminal nucleotide of WYMV siRNAs. (C) Sequence logo analysis of WYMV siRNAs. 21- and 22-nt WYMV siRNAs corresponding to RNA1 were separately analyzed, and the 4 nt proximal to the $5^{\prime}$ and $3^{\prime}$ ends of the siRNAs in the viral genome sequence were included in the analysis. The overall height of the stack indicates the sequence conservation at that position, while the height of characters within the stack indicates the relative frequency of nucleotide at that position.
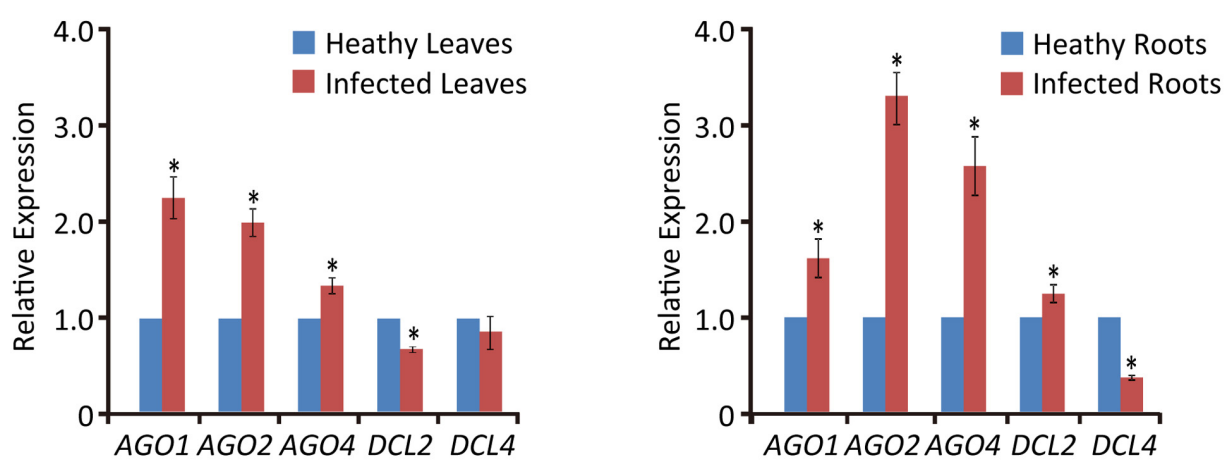

FIGURE 4 | Relative transcript expressions of wheat AGO1, AGO2, AGO4, DCL2, and DCL4 upon WYMV infection. Three biological replicates were performed in this experiment. Data are means $\pm \mathrm{SD}(n=3)$. Asterisk indicates significant difference at $P<0.01$ (one-way ANOVA).

\section{A/U Bias at the $5^{\prime}$-Terminal Nucleotide of vsiRNAs Was Higher in Leaves Than Roots}

The $5^{\prime}$-terminal nucleotide of sRNAs is important in their preferential recruitment by AGO complexes (Mi et al., 2008). Nucleotide bias toward adenine (A) or uracil (U) at the 5 -terminal is typical of vsiRNAs from various organisms including plants, fungi, and insects (Yan et al., 2010; Xu et al., 2012; Li et al., 2013; Mitter et al., 2013; Yang et al., 2014; Margaria et al., 2015, 2016; Yaegashi et al., 2016). Interestingly, our analysis showed that the A/U bias at the $5^{\prime}$-terminal nucleotide of 21 - and 22-nt vsiRNA was markedly higher in leaf libraries than in root libraries (Figure 3A). Analysis of the unique vsiRNAs showed that leaf-specific and common vsiRNAs have a typical strong $\mathrm{A} / \mathrm{U}$ preference, whereas root-specific vsiRNAs have no clear preference for the $5^{\prime}$-terminal nucleotide (Figure 3B). Sequence logo analysis ${ }^{4}$ (Crooks et al., 2004) was then performed on 21- and 22-nt vsiRNA (unique reads) including the $4 \mathrm{nt}$ proximal to the $5^{\prime}$ and $3^{\prime}$ ends of vsiRNA in the viral genome sequence to identify any sequence conservation within vsiRNAs and in the region surrounding their cleavage sites. No particular nucleotide conservation was found within the internal sequences of vsiRNAs or the surrounding cleavage sites, but the analysis

${ }^{4} \mathrm{http} / / /$ weblogo.berkeley.edu/logo.cgi 
confirmed that the $5^{\prime}$-terminal nucleotide of leaf-specific and to a lesser degree, common vsiRNAs (both polarities) were most frequently $A$ or $U$, whereas no such preference was observed in root-specific vsiRNAs (Figure 3C and Supplementary Figure S2).

In Arabidopsis thaliana, sRNAs with a $5^{\prime}$-terminal $\mathrm{A}$ are preferentially recruited by $\mathrm{AGO} 2$ and AGO4, while AGO1 favors sRNAs with a $5^{\prime}$-terminal $U$ (Montgomery et al., 2008; Takeda et al., 2008). The finding that vsiRNAs in plants typically have a strong $5^{\prime}$-terminal bias toward $\mathrm{A} / \mathrm{U}$ is therefore consistent with the antiviral role of AGO1, AGO2, and AGO4 (Carbonell and Carrington, 2015). In our experiments, the proportion of vsiRNAs with a $5^{\prime}$-terminal A or $U$ was markedly less in roots than leaves (Figures $\mathbf{3 A}, \mathbf{B}$ ). Thus although WYMV siRNAs were much more abundant in roots than leaves, it is possible that in roots only a small proportion of WYMV siRNAs are incorporated into RISCs and therefore that antiviral RNA silencing operates less efficiently against WYMV in roots. The reason for the differential $5^{\prime}$-terminal nucleotide profiles of WYMV siRNAs between roots and leaves remains unclear. It is possible that WYMV replication or WYMV-encoded protein(s) alter the normal DCL preferential cleavage sites for vsiRNA production in roots.

\section{Expression of Dicer-Like Genes Were Differently Regulated between Leaves and Roots during WYMV Infection}

Previous studies have shown that virus infection regulates the expression of RNA silencing-related genes in plants (Du et al., 2011; Conti et al., 2017; Sun et al., 2017). From our transcriptome analysis of wheat leaves (unpublished result), we have identified some RNA silencing-related genes including AGO1, AGO2, AGO4, DCL2, and DCL4 based on their homology to the proteins encoded by other plant species (Supplementary Table S2). RTqPCR analysis using the primers listed in Supplementary Table S1 showed that the transcription levels of wheat AGO1, AGO2, and $A G O 4$ in leaves and roots were significantly increased upon WYMV infection (Figure 4). Interestingly, wheat DCL2 transcripts were upregulated in roots but downregulated in leaves and wheat DCL4 transcripts were downregulated in roots but not in leaves upon WYMV infection (Figure 4). This result shows that WYMV infection affects the expression of DCL genes differently in leaves and roots. Studies using A. thaliana indicate that DCL4 and DCL2 generate 21and 22-nt vsiRNAs, respectively, in a hierarchical manner (Deleris et al., 2006; Diaz-Pendon et al., 2007). Interestingly, in WYMV-infected wheat plants, upregulation of DCL2 transcripts and downregulation of DCL4 transcripts in roots coincided with a slightly higher proportion of 22- to 21-nt vsiRNAs relative to that in leaves (Figures $\mathbf{1 C}, \mathbf{D}$ ). The percentages of 22- and 21-nt vsiRNAs in roots were $22.5 \pm 4.16$ and $57.8 \pm 3.04 \%$, while they were $16.3 \pm 2.42$ and $65.1 \pm 2.30 \%$ in leaves. Thus, WYMV infection in roots may affect the biogenesis of vsiRNAs by regulating transcript expression of $D C L$ genes.

\section{CONCLUSION}

In the present study, deep sequencing was used to characterize and compare the profiles of WYMV vsiRNA derived from leaves and roots of infected wheat plants. vsiRNAs in leaves and roots shared some similar characteristics in length distribution and polarity, while differed in abundance, hotspots distribution along viral genome and nucleotide bias at $5^{\prime}$ terminal. In addition, the expression of DCL genes (DCL2 and DCL4) was differently regulated between leaves and roots upon WYMV infection. Overall, our results suggest divergent operation of RNA silencing defense against soil-borne virus invasion in roots. Further studies are necessary to investigate how WYMV infection regulates the expression of RNA silencing-associated genes and whether the differential regulation of DCL2 and DCL4 transcripts in roots affects the general activities of those genes and their preferential cleavage sites.

\section{AUTHOR CONTRIBUTIONS}

JC and JL conceived and designed the experiments. LL, YX, YZ, $\mathrm{LH}$, and ZS performed the experiments. JL, IBA, GH, YC, FY, JY, and XX analyzed data. JC, JL, LL, and IBA wrote the manuscript.

\section{FUNDING}

This work was funded by the Special Fund for Agroscientific Research in the Public Interest of China (201303021), China Agriculture Research System (CARS-3-1) from the Ministry of Agriculture of China, the National Natural Science Foundation of China (31501604), the Project of New Varieties of Genetically Modified Wheat of China (2011ZX08002-001), and the International Science and Technology Cooperation Program of China (2015DFA30700).

\section{ACKNOWLEDGMENT}

We thank Mike J. Adams (Stevenage Herts, United Kingdom), for English correction of the manuscript.

\section{SUPPLEMENTARY MATERIAL}

The Supplementary Material for this article can be found online at: http://journal.frontiersin.org/article/10.3389/fmicb. 2017.01802/full\#supplementary-material

FIGURE S1 | Tissue-specific and common WYMV vsiRNAs (21 and 22 nt) based on unique reads. Three vsiRNA libraries (replicates) were mixed, and unique 21and 22-nt vsiRNAs were extracted.

FIGURE S2 | Sequence logo analysis of WYMV siRNAs. 21- and 22-nt WYMV siRNAs corresponding to RNA2 were separately analyzed, and the $4 \mathrm{nt}$ proximal to the $5^{\prime}$ and $3^{\prime}$ ends of the siRNAs in the viral genome sequence were included in the analysis. The overall height of the stack indicates the sequence conservation at that position, while the height of characters within the stack indicates the relative frequency of the nucleotide at that position.

FILE S1 | Viral small interfering RNA sequences in wheat leaves and roots. 


\section{REFERENCES}

Adams, M. J., Antoniw, J. F., and Beaudoin, F. (2005). Overview and analysis of the polyprotein cleavage sites in the family Potyviridae. Mol. Plant Pathol. 6, 471-487. doi: 10.1111/j.1364-3703.2005.00296.x

Adams, M. J., Antoniw, J. F., and Mullins, J. G. L. (2001). Plant virus transmission by plasmodiophorid fungi is associated with distinctive transmembrane regions of virus-encoded proteins. Arch. Virol. 146, 1139-1153. doi: 10.1007/ s007050170111

Ahlquist, P. (2002). RNA-dependent RNA polymerases, viruses, and RNA silencing. Science 296, 1270-1273. doi: 10.1126/science.1069132

Aliyari, R., and Ding, S. W. (2009). RNA-based viral immunity initiated by the Dicer family of host immune receptors. Immunol. Rev. 227, 176-188. doi: 10.1111/j.1600-065X.2008.00722.x

Andika, I. B., Kondo, H., Nishiguchi, M., and Tamada, T. (2012). The cysteine-rich proteins of beet necrotic yellow vein virus and tobacco rattle virus contribute to efficient suppression of silencing in roots. J. Gen. Virol. 93, 1841-1850. doi: 10.1099/vir.0.043513-0

Andika, I. B., Kondo, H., and Sun, L. (2016). Interplays between soil-borne plant viruses and RNA silencing-mediated antiviral defense in roots. Front. Microbiol. 7:1458. doi: 10.3389/fmicb.2016.01458

Andika, I. B., Kondo, H., and Tamada, T. (2005). Evidence that RNA silencingmediated resistance to beet necrotic yellow vein virus is less effective in roots than in leaves. Mol. Plant Microbe Interact. 18, 194-204. doi: 10.1094/MPMI18-0194

Andika, I. B., Sun, L., Xiang, R., Li, J., and Chen, J. (2013). Root-specific role for Nicotiana benthamiana RDR6 in the inhibition of Chinese wheat mosaic virus accumulation at higher temperatures. Mol. Plant Microbe Interact. 26, 1165-1175. doi: 10.1094/MPMI-05-13-0137-R

Bologna, N. G., and Voinnet, O. (2014). The diversity, biogenesis, and activities of endogenous silencing small RNAs in Arabidopsis. Annu. Rev. Plant Biol. 65, 473-503. doi: 10.1146/annurev-arplant-050213-035728

Carbonell, A., and Carrington, J. C. (2015). Antiviral roles of plant ARGONAUTES. Curr. Opin. Plant Biol. 27, 111-117. doi: 10.1016/j.pbi.2015.06.013

Conti, G., Zavallo, D., Venturuzzi, A. L., Rodriguez, M. C., Crespi, M., and Asurmendi, S. (2017). TMV induces RNA decay pathways to modulate gene silencing and disease symptoms. Plant J. 89, 73-84. doi: 10.1111/tpj. 13323

Crooks, G. E., Hon, G., Chandonia, J. M., and Brenner, S. E. (2004). WebLogo: a sequence logo generator. Genome Res. 14, 1188-1190. doi: 10.1101/gr.84 9004

Deleris, A., Gallego-Bartolome, J., Bao, J., Kasschau, K. D., Carrington, J. C., and Voinnet, O. (2006). Hierarchical action and inhibition of plant Dicerlike proteins in antiviral defense. Science 313, 68-71. doi: 10.1126/science.112 8214

Dessens, J. T., and Meyer, M. (1996). Identification of structural similarities between putative transmission proteins of Polymyxa and Spongospora transmitted bymoviruses and furoviruses. Virus Genes 12, 95-99. doi: 10.1007/ bf00370006

Diaz-Pendon, J. A., Li, F., Li, W. X., and Ding, S. W. (2007). Suppression of antiviral silencing by Cucumber mosaic virus $2 \mathrm{~b}$ protein in Arabidopsis is associated with drastically reduced accumulation of three classes of viral small interfering RNAs. Plant Cell 19, 2053-2063. doi: 10.1105/tpc.106. 047449

Ding, S. W. (2010). RNA-based antiviral immunity. Nat. Rev. Immunol. 10, 632-644. doi: 10.1038/nri2824

Du, P., Wu, J., Zhang, J., Zhao, S., Zheng, H., Gao, G., et al. (2011). Viral infection induces expression of novel phased microRNAs from conserved cellular microRNA precursors. PLOS Pathog. 7:e1002176. doi: 10.1371/journal. ppat. 1002176

Fletcher, S. J., Shrestha, A., Peters, J. R., Carroll, B. J., Srinivasan, R., Pappu, H. R., et al. (2016). The tomato spotted wilt virus genome is processed differentially in its plant host Arachis hypogaea and its thrips vector Frankliniella fusca. Front. Plant Sci. 7:1349. doi: 10.3389/fpls.2016.01349

Gosalvez-Bernal, B., Genoves, A., Navarro, J. A., Pallas, V., and Sanchez-Pina, M. A. (2008). Distribution and pathway for phloem-dependent movement of Melon necrotic spot virus in melon plants. Mol. Plant Pathol. 9, 447-461. doi: $10.1111 / \mathrm{j} .1364-3703.2008 .00474 . \mathrm{x}$
Hadidi, A., Flores, R., Candresse, T., and Barba, M. (2016). Next-generation sequencing and genome editing in plant virology. Front. Microbiol. 7:1325. doi: $10.3389 /$ fmicb.2016.01325

Han, C., Li, D., Xing, Y., Zhu, K., Tian, Z., Yu, J., et al. (2000). Wheat yellow mosaic virus widely occurring in wheat (Triticum aestivum) in China. Plant Dis. 84, 627-630. doi: 10.1094/PDIS.2000.84.6.627

Hull, R. (2013). Plant Virology. Cambridge, MA: Academic Press.

Kanyuka, K., Ward, E., and Adams, M. J. (2003). Polymyxa graminis and the cereal viruses it transmits: a research challenge. Mol. Plant Pathol. 4, 393-406. doi: 10.1046/j.1364-3703.2003.00177.x

Kashiwazaki, S. (1996). The complete nucleotide sequence and genome organization of barley mild mosaic virus (Nal strain). Arch. Virol. 141, 2077-2089. doi: 10.1007/BF01718216

Kashiwazaki, S., Minobe, Y., and Hibino, H. (1991). Nucleotide sequence of barley yellow mosaic virus RNA 2. J. Gen. Virol. 72(Pt 4), 995-999. doi: 10.1099/00221317-72-4-995

Kutnjak, D., Rupar, M., Gutierrez-Aguirre, I., Curk, T., Kreuze, J. F., and Ravnikar, M. (2015). Deep sequencing of virus-derived small interfering RNAs and RNA from viral particles shows highly similar mutational landscapes of a plant virus population. J. Virol. 89, 4760-4769. doi: 10.1128/JVI.03685-14

Li, J., Andika, I. B., Shen, J., Lv, Y., Ji, Y., Sun, L., et al. (2013). Characterization of rice black-streaked dwarf virus- and rice stripe virus-derived siRNAs in singly and doubly infected insect vector Laodelphax striatellus. PLOS ONE 8:e66007. doi: 10.1371/journal.pone.0066007

Li, J., Zheng, H., Zhang, C., Han, K., Wang, S., Peng, J., et al. (2016). Different virusderived siRNAs profiles between leaves and fruits in Cucumber green mottle mosaic virus-infected Lagenaria siceraria plants. Front. Microbiol. 7:1797. doi: 10.3389/fmicb.2016.01797

Li, M. L., Weng, K., Shih, S., and Brewer, G. (2016). The evolving world of small RNAs from RNA viruses. Wiley Interdiscip. Rev. RNA 7, 575-588. doi: 10.1002/ wrna. 1351

Llave, C. (2010). Virus-derived small interfering RNAs at the core of plant-virus interactions. Trends Plant Sci. 15, 701-707. doi: 10.1016/j.tplants.2010.09.001

Margaria, P., Miozzi, L., Ciuffo, M., Rosa, C., Axtell, M. J., Pappu, H. R., et al. (2016). Comparison of small RNA profiles in Nicotiana benthamiana and Solanum lycopersicum infected by Polygonum ringspot tospovirus reveals hostspecific responses to viral infection. Virus Res. 211, 38-45. doi: 10.1016/j. virusres.2015.09.019

Margaria, P., Miozzi, L., Rosa, C., Axtell, M. J., Pappu, H. R., and Turina, M. (2015). Small RNA profiles of wild-type and silencing suppressor-deficient Tomato spotted wilt virus infected Nicotiana benthamiana. Virus Res. 208, 30-38. doi: 10.1016/j.virusres.2015.05.021

Mi, S., Cai, T., Hu, Y., Chen, Y., Hodges, E., Ni, F., et al. (2008). Sorting of small RNAs into Arabidopsis argonaute complexes is directed by the $5^{\prime}$ terminal nucleotide. Cell 133, 116-127. doi: 10.1016/j.cell.2008.02.034

Mingot, A., Valli, A., Rodamilans, B., San Leon, D., Baulcombe, D. C., Garcia, J. A., et al. (2016). The P1N-PISPO trans-frame gene of sweet potato feathery mottle Potyvirus is produced during virus infection and functions as an RNA silencing suppressor. J. Virol. 90, 3543-3557. doi: 10.1128/JVI.02360- 15

Mitter, N., Koundal, V., Williams, S., and Pappu, H. (2013). Differential expression of Tomato spotted wilt virus-derived viral small RNAs in infected commercial and experimental host plants. PLOS ONE 8:e76276. doi: 10.1371/journal.pone. 0076276

Molnar, A., Csorba, T., Lakatos, L., Varallyay, E., Lacomme, C., and Burgyan, J. (2005). Plant virus-derived small interfering RNAs originate predominantly from highly structured single-stranded viral RNAs. J. Virol. 79, 7812-7818. doi: 10.1128/JVI.79.12.7812-7818.2005

Montgomery, T. A., Howell, M. D., Cuperus, J. T., Li, D., Hansen, J. E., Alexander, A. L., et al. (2008). Specificity of ARGONAUTE7-miR390 interaction and dual functionality in TAS3 trans-acting siRNA formation. Cell 133, 128-141. doi: 10.1016/j.cell.2008.02.033

Namba, S., Kashiwazaki, S., Lu, X., Tamura, M., and Tsuchizaki, T. (1998). Complete nucleotide sequence of wheat yellow mosaic bymovirus genomic RNAs. Arch. Virol. 143, 631-643. doi: 10.1007/s007050050319

Naveed, K., Mitter, N., Harper, A., Dhingra, A., and Pappu, H. R. (2014). Comparative analysis of virus-specific small RNA profiles of three biologically distinct strains of Potato virus $Y$ in infected potato (Solanum tuberosum) cv. Russet Burbank. Virus Res. 191, 153-160. doi: 10.1016/j.virusres.2014.07.005 
Ogwok, E., Ilyas, M., Alicai, T., Rey, M. E., and Taylor, N. J. (2016). Comparative analysis of virus-derived small RNAs within cassava (Manihot esculenta Crantz) infected with cassava brown streak viruses. Virus Res. 215, 1-11. doi: 10.1016/j. virusres.2016.01.015

Sun, D., Li, S., Niu, L., Reid, M. S., Zhang, Y., and Jiang, C. Z. (2017). PhOBF1, a petunia ocs element binding factor, plays an important role in antiviral RNA silencing. J. Exp. Bot. 68, 915-930. doi: 10.1093/jxb/erw490

Sun, L., Andika, I. B., Shen, J., Yang, D., and Chen, J. (2014). The P2 of Wheat yellow mosaic virus rearranges the endoplasmic reticulum and recruits other viral proteins into replication-associated inclusion bodies. Mol. Plant Pathol. 15, 466-478. doi: 10.1111/mpp.12109

Takeda, A., Iwasaki, S., Watanabe, T., Utsumi, M., and Watanabe, Y. (2008). The mechanism selecting the guide strand from small RNA duplexes is different among argonaute proteins. Plant Cell Physiol. 49, 493-500. doi: 10.1093/pcp/ pcn043

Tatineni, S., Qu, F., Li, R., Morris, T. J., and French, R. (2012). Triticum mosaic poacevirus enlists $\mathrm{P} 1$ rather than HC-Pro to suppress RNA silencingmediated host defense. Virology 433, 104-115. doi: 10.1016/j.virol.2012. 07.016

Untiveros, M., Olspert, A., Artola, K., Firth, A. E., Kreuze, J. F., and Valkonen, J. P. (2016). A novel sweet potato potyvirus open reading frame (ORF) is expressed via polymerase slippage and suppresses RNA silencing. Mol. Plant Pathol. 17, 1111-1123. doi: $10.1111 / \mathrm{mpp} .12366$

Valli, A., Martín-Hernández, A. M., López-Moya, J. J., and García, J. A. (2006). RNA silencing suppression by a second copy of the P1 serine protease of Cucumber vein yellowing ipomovirus, a member of the family Potyviridae that lacks the cysteine protease HCPro. J. Virol. 80, 10055-10063. doi: 10.1128/JVI.00 985-06

Valli, A. A., Gallo, A., Rodamilans, B., Lopez-Moya, J. J., and Garcia, J. A. (2017). The HCPro from the Potyviridae family: an enviable multitasking Helper Component that every virus would like to have. Mol. Plant Pathol. doi: 10.1111/ mpp.12553 [Epub ahead of print].
Xu, Y., Huang, L., Fu, S., Wu, J., and Zhou, X. (2012). Population diversity of rice stripe virus-derived siRNAs in three different hosts and RNAi-based antiviral immunity in Laodelphgax striatellus. PLOS ONE 7:e46238. doi: 10.1371/journal. pone. 0046238

Yaegashi, H., Shimizu, T., Ito, T., and Kanematsu, S. (2016). Differential inductions of RNA silencing among encapsidated double-stranded RNA mycoviruses in the white root rot fungus Rosellinia necatrix. J. Virol. 90, 5677-5692. doi: 10.1128/JVI.02951-15

Yan, F., Zhang, H., Adams, M. J., Yang, J., Peng, J., Antoniw, J. F., et al. (2010). Characterization of siRNAs derived from rice stripe virus in infected rice plants by deep sequencing. Arch. Virol. 155, 935-940. doi: 10.1007/s00705-010-0670-8

Yang, J., Zheng, S. L., Zhang, H. M., Liu, X. Y., Li, J., Li, J. M., et al. (2014). Analysis of small RNAs derived from Chinese wheat mosaic virus. Arch. Virol. 159, 3077-3082. doi: 10.1007/s00705-014-2155-7

Zhang, C., Wu, Z., Li, Y., and Wu, J. (2015). Biogenesis, function, and applications of virus-derived small RNAs in plants. Front. Microbiol. 6:1237. doi: 10.3389/ fmicb.2015.01237

Zhu, H., and Guo, H. (2012). The role of virus-derived small interfering RNAs in RNA silencing in plants. Sci. China Life Sci. 55, 119-125. doi: 10.1007/s11427012-4281-3

Conflict of Interest Statement: The authors declare that the research was conducted in the absence of any commercial or financial relationships that could be construed as a potential conflict of interest.

Copyright (c) 2017 Li, Andika, Xu, Zhang, Xin, Hu, Sun, Hong, Chen, Yan, Yang, Li and Chen. This is an open-access article distributed under the terms of the Creative Commons Attribution License (CC BY). The use, distribution or reproduction in other forums is permitted, provided the original author(s) or licensor are credited and that the original publication in this journal is cited, in accordance with accepted academic practice. No use, distribution or reproduction is permitted which does not comply with these terms. 